\title{
JUURNAL_RU
}

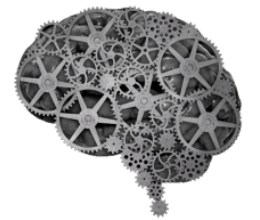

COMPANY GROUP "INTELLEKT"

\author{
Беляева К.Д. \\ ФГБОУ ВПО «Государственный университет управления» \\ Москва, Россия
}

doi: 10.18411/1j2016-5-2-03

\section{Особенности налогового контроля в РФ}

Аннотация: В статье рассматривается налоговый контроль РФ, его предмет, объект, а так же виды налогового контроля и особенности. В конце исследования делаются основные выводы с целью исключения или минимизации негативных тенденций и последствий в процессе налогового контроля.

Ключевые слова: налоги, налоговый контроль, налогоплательщик, законодательство, бюджетная система, доходы.

Одним из ведущих направлений в сфере государственного финансового контроля является так называемый налоговый контроль. Во многом за счет данного механизма достигается упорядоченность правоотношений в налоговом поле. Органами соответствующего контроля производится проверка соблюдения налогоплательщиком нормативно правовых актов о сборах и налогах. В данном контексте, в частности по уплате налогов, как правило, выявляются отдельные противоправные действия, которые через требования, а в последующем судебные акты, подлежат взысканию в виде уплаты или взыскания налогов, штрафных санкций и пени. От деятельности органов соответствующего контроля зависят решения многих проблем социального характера, обеспечение безопасности и экономической независимости государства. Более того, основной целью социально-экономической политики является создание и 
повышение эффективности системы контроля с целью обеспечения доходов в бюджет.

Важно отметить, что все вышеперечисленное составляет актуальность настоящего исследования, цель которой сводится к исследованию и анализу особенностей контроля в налоговой сфере на примере Российской Федерации.

Автором в статье ставятся следующие задачи:

- дать определение понятию «налоговый контроль», раскрыть объект и предмет;

- раскрыть основные виды и формы соответствующей деятельности на примере Российской Федерации;

- выявить и дать оценку особенностям контроля над налогами.

Под налоговым контролем следует понимать деятельность должностных лиц налогового органа, которая связана с контролем за своевременностью и правильностью уплаты установленных на законодательном уровне сборов и налогов, в рамках предоставленных законом компетенций.

Соответственно объектом контроля в налоговой сфере являются либо действия, либо бездействия налогоплательщиков, плательщиков сборов, налоговых агентов и иных лиц, которые обязаны уплачивать соответствующие сборы и налоги. Кроме того в качестве объекта могут выступать исполнение иных обязанностей, которые предусмотрены налоговым законодательством, которые можно оценить с позиции их законности, своевременности и достоверности.

Предметом контроля могут выступать вещественные, документальные и цифровые носители информации по совершенным налогоплательщиками операциям, его действиях или бездействии. Иными словами к их числу можно отнести бухгалтерскую документацию, договоры, сметы, отчеты, платежные ордера и счет-фактуры, декларации и т.д.

Под формой налогового контроля следует понимать способ организации, осуществления и формального закрепления полученных результатов 
мероприятий налогового контроля. Последние представляют собой единство в действиях уполномоченных органов по выполнению задач соответствующего контроля.

В настоящее время статьей 82 НК РФ регламентированы следующие формы проведения налогового контроля:

- проверки (выездные, камеральные и т.д,);

- получение объяснений с налоговых агентов, плательщиков сборов и налогов;

- проверка данных отчетности и учета;

- обследование и осмотр территорий и помещений, которые используются для извлечения прибыли (например, офисов, морских и речных портов и т.д.);

- иные формы (налоговые посты) [3,c. 83].

Ключевым федеральным органом исполнительной власти на территории РФ в сфере контроля и надзора за соблюдением налогового законодательства является Федеральная налоговая служба России (ФНС). Указанная выше служба призвана следить за правильностью и достоверностью исчисления сборов, налогов и иных платежей обязательного характера, а также за своевременностью их внесения в бюджеты разного уровня (муниципальный, региональный, федеральный). В обязанности ФНС также входит отслеживание оборота и производства табачных изделий, а также в сфере соблюдения валютного законодательства в рамках соответствующих компетенций.

Важно подчеркнуть, что большинство полномочий осуществляется через территориальные органы ФНС. Кроме того, через них осуществляется взаимодействие в области контроля и регулирования налогообложения с муниципальными, региональными и федеральными органами власти, а также с внебюджетными государственными фондами и прочими учреждениями [2].

В зависимости от времени проведения процедуры налогового контроля пот отношению к тем или иным финансово-хозяйственным операциям 
различают предварительный, оперативный и последующий налоговый контроль:

Первый тип осуществляется с целью предупреждения возможных нарушений в сфере финансового законодательства и призван выявить их на стадии планирования и прогнозирования дополнительных финансовых ресурсов, а также пресечь определенные действия, связанные с нерациональным использованием финансовых ресурсов. Кроме того, данному типу отводится роль в части помощи малому бизнесу в организации бухгалтерского учета и отчетности, то есть в данном контексте речь идет исключительно о посильной помощи в части организации данного процесса на ранних стадиях.

Второй тип (оперативный или текущий контроль) на ежедневной основе осуществляется силами финансовых служб для предотвращения нарушений в сфере финансовой дисциплины в процессе привлечения и последующего расходования финансовых ресурсов, выполнениями субъектами обязательств перед бюджетами разного уровня. В сфере налогообложения такой контроль является проверкой, которая проводится в отчетном периоде в целях оценки правильности отражения различного рода финансовых операций (в том числе трансакций) и достоверности данных бухгалтерской документации, представляемой плательщиками.

И, наконец, третий тип (последующий контроль) заключается в проверке финансово-хозяйственных операций за отчетный период с опорой на анализ балансов и отчетов, а также посредством проведения выездных ревизий и проверок: в учреждениях, на предприятиях и организациях. Представленный контроль проводится методом документальной проверки, который характеризуется углубленным изучением финансово-хозяйственной деятельности. Более того, такие возможности позволяют вскрыть имеющиеся недостатки.

Таким образом, налоговый контроль является разновидностью как финансовой деятельности, так и управленческой деятельности в сфере налогов. 
В связи с этим в зависимости от характера проверяемых субъектов выделяют контроль:

- таможенных органов;

- налоговых органов;

- органов государственных внебюджетных фондов.

От места проведения указанных процедур выделяют следующие виды налогового контроля:

- камеральный, то есть непосредственно по месту «дислокации» налогового органа;

- выездной, то есть по месту нахождения налогоплательщика.

В современной налоговой системе существует ряд особенностей, в частности в данном контексте речь идет о сложившейся на современном этапе бюрократической системе отчетности по сравнению с предыдущими десятилетиями. Следует обратить внимание на затягивание процедуры приема отчетности. В связи с тем, что в территориальных налоговых службах прошла оптимизация штатной численности создаются очереди. Достаточно часто изменяются формы деклараций и отчетности, а также подходы и методы в их непосредственном заполнении [6, с.6].

Рядом российских исследователей указанного вопроса выделяется проблема продуктивности контроля. Иными словами, относительно выше сказанного аспекта следует заметить, что на данный момент нет полноценной возможности к обеспечению государственных расходов соответствующими налоговыми поступлениями в полной мере. Одной из причин следует считать завышенные издержки, связанные с взиманием налогов над величиной налоговых поступлений. Примером тому могут служить налоговые уведомления, которые приходят на несколько рублей, при этом государство несет издержки на почтовые отправления, которые стоят гораздо дороже взимаемых средств. Последнее оказывает негативное воздействие, в том числе на результат налогового контроля [5, с.41]. 
Кроме того, по статистике $10 \%$ проверок налогоплательщиков были проведены с участием правоохранительных органов, данные испытаний составила $30 \%$ дополнительных расходов (52,8 миллиарда долларов.) Это не говорит о преимуществах участия сотрудников МВД в налоговых проверках, принимается только тот факт, что основная сумма дополнительных расходов требуется производить в соответствии с положениями в уклонении от уплаты налогов, схема доказательства, как правило, требует большого количества допросов, что, конечно же, быстрее делается сотрудниками МВД. По одной проверке в среднем за прошлый год доначислялось 5,7 млн. рублей [4, с.143].

Исследуя камеральную проверку, следует отметить, что определенной особенностью указанной формы являются подходы к проведению. Так, например, если налогоплательщик не предоставляет декларацию, то отсутствуют основания для проведения камеральной проверки.

Таким образом, следует сделать ряд выводов:

- с целью сокращения очередей и оптимизации процедуры контроля следует интегрировать в процесс контроля электронные формы документооборота;

- необходимо оптимизировать издержки по взиманию сборов и налогов, в том числе посредством СМС - информирования, при этом налогоплательщик обязуется сообщать в налоговый орган по месту жительства свой номер телефона;

- разработать универсальную форму декларации, сократить количество изменений до минимума в определенный период времени с целью сокращения бюрократических проволочек;

- следует модернизировать текущее законодательство с целью обеспечения наилучших условий для проведения процедур налогового контроля [1, С.210]. 


\section{Литература:}

1. Алимирзоева М.Г. Пути повышения эффективности налогового контроля в РФ // Достижения вузовской науки. - 2014. - № 10. - С. 207-211.

2. Бизнес журнал «Ве Prime». Органы государственного налогового контроля. // Режим доступа: http://beprime.ru/

3. Галимова И.В. Проблемы налогового контроля в РФ // В сборнике: XVIII ЦАРСКОСЕЛЬСКИЕ ЧТЕНИЯ Под общей редакцией профессора В. Н. Скворцова. - 2014. - С. 80-84.

4. Григорьева И.Н. Особенности налогового контроля в России // Сибирский торгово-экономический журнал. - 2014. - № 1 (19). - С. 141-143.

5. Митасова А.Ю., Макеева А.С., Федотова Г.В. Особенности налогового контроля в России // Управление. Бизнес. Власть. - 2015. - № 4 (9). - С. 3942.

6. Сидельников А.Р., Саркисян Э.П. Новая форма налогового контроля: особенности и перспективы развития // Международный студенческий научный вестник. - 2015. - № 1. - С. 6. 